\title{
Angry Young Men? A product of their time.
}

By the end of the 1950s what I term a 'working-class moment' in British culture had begun to emerge. This 'working-class moment' is most commonly associated with the democratising tendencies of the 1960s and the success, and cultural significance, of working-class figures such as The Beatles, David Bailey, George Best, Michael Caine and Terrence Stamp, but its origins are firmly rooted in a pattern of commodification of working-class masculinities that emerged in 1950s Britain. This chapter utilises Raymond Williams's concept of 'structure of feeling' (1954: 21) to trace the origin of that commodification to the emergence of new discourses of masculinities from the 'Movement' novels of Kingsley Amis and John Wain, through the so-called 'Angry Young Men', before focusing upon a less easily distinguishable, but discrete and significant, pattern of (largely) Northern realism in British fiction.

'Structure of feeling' is a key concept within the academic project of Raymond Williams, initially deployed in Preface to Film (1954) its genesis is contemporaneous with Wain's Hurry on Down (1953) and Amis's Lucky Jim (1954), as such the concept itself belongs to a structure of feeling in which the standards and conventions of British culture and society were being challenged. 'Structure of feeling' remains a contentious concept, due, at least in part, to the fact that the concept and its definitions have remained elusive and ambiguous. However, there are three distinct phases in the development of the concept, which, whilst not entirely discrete, are recognisably different. Williams's original use of the concept in Preface to Film clearly indicates his intention to provide an alternative interpretative framework for Marxist cultural analysis. It demonstrates a direct challenge to the existing orthodox Marxist formula in which cultural production is understood to be a superstructural corollary of the economic base, and presents as the foundational stage of a cultural hypothesis that seeks to break down the perceived barriers between 'culture' and 'society', between the 'social' and the 'personal'. The term itself, which Williams acknowledges is 'difficult' (1977: 132), with its inherent contradiction between the definite 
'structure', and the intangible 'feeling' points us toward this conclusion. Williams further developed the concept of 'structure of feeling' in The Long Revolution (1961), a text which continues the inquiry begun in Williams's Culture \& Society: 1780-1950 (1958).

This second phase in the development of the concept is contemporaneous with the texts studied here, Alan Sillitoe's Saturday Night and Sunday Morning (1958) and David Storey's This Sporting Life (1960), and marks the genesis of what would eventually become the practice of 'cultural materialism' (1977: 5). In The Long Revolution Williams describes the difficulty of 'get[ting] hold of the 'felt sense of the quality of life at a particular place and time: a sense of the ways in which the particular activities combined into ways of thinking and living' ([1961] 1965: 63). Williams recognises the value of Fromm's concept of 'the "social character"” and Benedict's concept of 'the "pattern of culture" in attempting to 'restor[e] the outlines of a particular organization of life', but notes that in each case the "way of life" that is recovered is 'usually abstract' ([1961] 1965: 63-4). Williams continues to suggest that it may be possible to 'gain the sense of a further common element, which is neither the character nor the pattern, but as it were the actual experience through which these were lived' ([1961] 1965: 64). Williams states that when 'the arts of a period', are 'measured [...] against the external characteristics of the period' there can still exist 'some important common element that we cannot easily place', this is precisely what Williams terms 'structure of feeling' ([1961] 1965: 64). According to Williams, 'structure of feeling' is a concept that 'is as firm and definite as "structure" suggests, yet it operates in the most delicate and least tangible parts of our activity' ([1961] 1965: 64). The key element of this phase of the concept is the recognition of the central position the arts occupy in the analysis of culture as a whole way of life, and how the arts enable us to understand changes within the system of social reproduction. It becomes apparent in the study of the arts that a structure of feeling is not formally learned, but emerges from generationally specific reactions, and interactions, to, and with, the culture and society that is in existence in a particular time and place. As Williams states, '[o]ne generation may train its successor, with reasonable success, in the social character or the general cultural pattern, 
but the new generation will have its own structure of feeling, which will not appear to have come "from" anywhere' ([1961] 1965: 64). Although the appropriateness of structures of feeling as a means through which to study the emergence of new forms of working-class masculinities is already apparent in the second phase of concept, at this stage of its development the scope of the concept is still rather broad, and is complicated by its focus on the reconciliation of culture and society.

The third phase of the development of the concept of structures of feeling sees Williams embed the concept as a practical means of conducting textual analysis within the broader practice of cultural materialism. Williams introduced the practice of cultural materialism as 'a theory of the specificities of material cultural and literary production within historical materialism' in Marxism and Literature (1977: 5). With the development of cultural materialism Williams supersedes the attempts to reconcile 'culture' and 'society' that form the basis of his earlier work, positing instead that culture is always already social and material and must therefore be read as such. Williams argues that writing is a practice undertaken under definite social relations, and therefore cannot be understood as an autonomous cultural category, or as an object that reflects a given reality. Literature is an inalienable element of the complex social processes that constitute culture, and thus has a specificity that cannot be reduced. In this respect, the category of 'literature' itself becomes problematic as it serves as an exclusionary term that is given to certain types of writing in the construction of a 'selective tradition' (1977: 115). Williams describes the selective tradition as 'an intentionally selective version of a shaping past and a pre-shaped present, which is powerfully operative in the process of social and cultural definition and identification', argues that 'this selection is presented and usually successfully passed off as "the tradition", "the significant past", and concludes that, in this sense, any tradition is 'an aspect of the contemporary social and cultural organization, in the interest of the dominance of a specific class' that offers 'a sense of predisposed continuity' (1977: 115-6). Cultural materialism is a direct challenge not only to orthodox Marxist configurations of cultural production, but also to the idea of the validity of this selective tradition. 
As cultural materialism develops its robust theoretical framework, its direct antecedent 'structure of feeling' becomes a tool for textual analysis within this framework. Although still developing, by 1954, the concept represents a practical (and radical) means of understanding lived experience through the analysis of cultural texts.

In understanding structures of feeling as an analytical procedure it is possible to consider how the concept might be practically applied, Williams states:

We are talking about the characteristic elements of impulse, restraint, and tone; specifically affective elements of consciousness and relationships: not feeling against thought, but thought as felt and feeling as thought: practical consciousness of a present kind, in a living and interrelating continuity. We are then defining these elements as a 'structure': as a set, with specific internal relations, at once interlocking and in tension. Yet we are also defining a social experience which is still in process, often indeed not yet recognized as social but taken to be private, idiosyncratic, and even isolating, but which in analysis [...] has its emergent, connecting, and dominant characteristics, indeed its specific hierarchies (1977: 132).

In 'defining' the 'specific internal relations' which are 'at once interlocking and in tension' as a 'structure', structures of feeling account for, and become apparent through, the relationship between dominant, residual, and emergent cultural forms. Williams continues to methodologically define structure of feeling as, 'a cultural hypothesis, actually derived from attempts to understand such elements and their connections in a generation or period' (1977: 132-3). My use of structures of feeling here is twofold. It is employed both as a means to identify and analyse emergent forms of working-class masculinities at the end of the 1950s, and, through re-evaluating texts which belong to a 'selective tradition' of working-class writing, as a means to examine the cultural and 
commercial conditions under which the commodification of working-class masculinities which led to a 'working-class moment' in British culture occurred.

The structure of feeling from which the 'Angry Young Men' label emerges is evident in a number of novels published in the decade that followed the Second World War. These novels take a young, disaffected, usually lower-middle-class and university educated, male as their protagonist and are usually episodic in structure and comic in tone. They commonly explore themes of entrapment and escape, particularly in relation to the renegotiation of gendered (particularly masculine) identities, issues of employment, the sexual relationships of their protagonists and the continuation of the rigid class stratification of British society in the post-war period. Philip Larkin's Jill (1946) is notable as an early example of such texts and prefigures what Stuart Laing describes as 'a considerable cultural trend' (1984: 158) that emerged with the 'Movement' novels of Amis and Wain, although Roland Camberton's Scamp (1950) and Alexander Trocchi's Young Adam (1954) clearly demonstrate that this emergent pattern was not solely generated by writers associated with the 'Movement' label. The writing generated by the 'Movement' more broadly took Britain's diminished colonial power and influence in world politics as major themes, and represented the move to a more urban, industrial, consumer driven society, and the decline of an older more pastoral Britain with a nostalgic melancholy. This is significant as it demonstrates the sociocultural and historical specificities that underpinned the writing being discussed, and, the shift in tone and approach that occurred in 1956.

The identification of 1956 as a significant cultural moment in Britain is by no means new. John Osborne's Look Back in Anger (1956) is frequently offered up as a moment of rupture or discontinuity, the moment at which a new and distinct pattern of representation emerged within British culture, and the play which gave rise to the term 'Angry Young Men'. The retrospective inclusion of writers such as Amis and Wain under the 'Angry' banner clearly demonstrates the culturally constructed nature of the 'Angry Young Men' as a literary movement or category, and 
how the pervasive use of the term serves to obscure the nuances of a structure of feeling which gradually develops during the immediate post-war period. The inauthentic, opportunistic, journalistic and commercially driven nature of the 'Angry Young Men' label has been comprehensively written about elsewhere (See: Allsop, 1964, Bentley, 2007, 2010, Ferrebe, 2005, Maschler, [1957] 1959), suffice to say here that the term should be treated with caution. What the term does do however, is serve to create the cultural and commercial conditions from which a 'working-class moment' can emerge.

The work which was first collected under the 'Angry Young Men' label (including that to which it was retrospectively applied) was very much about the alienation and frustrations of a section of the educated lower-middle-class, as such the work can be said to prefigure the 'antiestablishment spirit' of what Eric Hopkins terms 'the permissive society' (1991: 178) of the 1960s. Laing identifies a period between 1957-1964 in which a structure of feeling where 'an unusual degree of overlap between previously (and subsequently) quite rigidly stratified cultural sectors in Britain' (1984: 158) becomes apparent. It is during this period that Laing identifies an emergent 'realist style frequently with regional, usually Northern, and working-class content' that was 'simultaneously at the forefront of serious artistic practice and available (and on offer) to a very large popular audience' (1984: 158). In the introduction to the 1964 edition of Kenneth Allsop's The Angry Decade he identifies a 'later wave' of Northern 'Angry' writers which is founded upon that of the 'angry school of fiction' of the 'middle fifties', according to Allsop, these writers, who include Alan Sillitoe and David Storey, approach their subjects from a 'very different angle to that mockingly mutinous jeering of the Redbrick boys of a few years earlier' (1964: 8). There is a definite shift in discourse at this point, from what Morton Kroll describes as stories of 'young men with all or a substantial part of a university education and of financially difficult middle-class and proletarian backgrounds' (1959: 556), to stories which focused on the lives of part-educated, or uneducated, proletariat by a number of authors who David James describes as 'northern regionalists' (2008: 42). Jane Mansfield suggests 'northerness is an integral factor' (2010: 34) within 
these texts. She continues to argue that the re-emergence of what she terms the 'brute-hero', connects to 'a reappraisal of masculinity during a period of national insecurity', and 'reflects issues of class-mobility in which the dominance of a particular type of masculinity surges forward in an act of class-transition' (2010: 34). What Mansfield alludes to here, are representations that emerge from tensions between residual and emergent masculinities, that become apparent at a time of great sociocultural change, she continues to offer a convincing argument which categorises these works as '[c]ondition of England fiction' and connects the 'brute hero' characters of this Northern realism to 'earlier rebellious figures of the North' (2010: 34). What becomes apparent in the work of Sillitoe and Storey then, is the emergence of new discourse around a specific formation of working-class masculinity, elements of which build on statements around, and offer some continuation to, the concept of the 'Angry Young Man', but in which Northerness itself becomes a significant means of articulating a specific kind of masculinity and its relation to contemporary shifts in the structures of class.

As early as 1957 Tom Maschler suggests that 'the writers who have set themselves the task of waking us up have been rendered harmless in the A.Y.M. cage' ([1957] 1959: 7). This is a striking image - an angry masculinity caged by 'the strenuous efforts of the Press' ([1957] 1959: 8) - which does little to suggest that the momentum created by the initial wave of 'Angry Young Men' would continue and develop. However, Maschler continues to assert that the anger of the writers 'has proved a highly saleable commodity' ([1957] 1959: 8). Again, this view is supported by Kroll, who asserts that 'Angry Young Men' is a 'highly marketable label' (1959: 555). This is significant as it points towards the incorporation of an oppositional cultural form. In fact, it suggests the commodification of a specific mode of masculinity and its concomitant forms of representation. The commodification and incorporation of an emergent form of cultural resistance, which created the material conditions necessary for the continued production of this type of cultural output. In turn, this formed part of a performative loop which fed into the construction, representation, and commodification of a new formulation of working-class masculine identities. It is to these 
masculinities, specifically the characters and cultures represented within Alan Sillitoe's Saturday Night and Sunday Morning (1958), and David Storey's This Sporting Life (1960), that I now turn.

The landscapes of Saturday Night and Sunday Morning and This Sporting Life form a central stake in the construction of the masculinities represented within the texts. Much like the 'Movement' texts which preceded them, in both texts there is a sense in which 'the country' is reduced to symbolic form, to the perception of residual cultures that serve as totems of an earlier, simpler and happier rural England. Yet both texts resist a representation of the country which is completely sentimental. As James notes, 'Sillitoe refuses to let his own sensuous prospect of that home-county sentimentalize the townscape it enframes. [...] Instead, Saturday Night's symbolism complements its scrutiny' (2008: 51). Further, in a continuation of the themes that inform the 'Movement' and 'Angry' novels that precede them, 'the country', or the suburbs that are slowly eroding it, become places of escape and entrapment. Escape in that they offer sanctuary, a location to which the protagonists can retreat and be away from the battles which form their daily existence. Entrapment in that, invariably, those battles are internalised and travel with the protagonists, and in that the country, though accessible, cannot be traversed. In this sense, the country, literally frames the urban settings of the novels, showing them in stark relief, and interning them and their inhabitants. The achievement of the country vignettes in both Saturday Night and Sunday Morning and This Sporting Life is the representation of the persistence of certain romantic cultural ideals, the patriarchal nuclear family, or the self-provisioning working-class; and a sense of how changes to the rhythms, and the material and social conditions of working-class life, cut across those residual forms. The tensions between persistence and change are represented elsewhere in the texts, as in the fact that Arthur Seaton still lives at home despite his emergent power as a consumer. However, the country vignettes situate these tensions within the wider historical context of dislocation, and thus, best demonstrate the interplay between emergent, residual, and dominant cultural forms, and the forms of masculinity, of this particular structure of feeling. 
Saturday Night and Sunday Morning is interspersed with vignettes in which Arthur Seaton visits the countryside. Significantly, these are the scenes in which Arthur seems most contented, or at least more relaxed. In a particularly telling scene Arthur remembers his grandfather 'who had been a blacksmith, and had a house and forge at Wollaton village' ([1958] 1961: 178-9). Of the smith's forge Sillitoe writes:

[1ts memory was a fixed picture in Arthur's mind. The building - you had drawn your own water from a well, dug your own potatoes out of the garden, taken eggs from the chicken run to fry with the bacon off your own side of pig hanging salted from a hook in the pantry ([1958] 1961: 179).

The sentimentality with which the building and the fantasy of the way of life that accompanies it are represented suggests what Williams refers to as 'a myth functioning as memory' ([1973] 1975: 57). In this sense Arthur's fantasy conjures an ever-receding 'golden age' (Williams, [1973] 1975: 48), which functions as a tenet within the construction of the idea of community. This passage serves to bring the change and discontinuity experienced by the working-class of the 1950s into sharp relief, whilst simultaneously demonstrating Sillitoe's acute awareness of the continuities of working-class life, particularly as the passage is qualified by the acknowledgement that the forge 'had long ago been destroyed to make room for advancing armies of new pink houses' ([1958] 1961: 179). These new pink houses are the new Nottingham suburbs that would rehouse many of the city's working-class, and which, paradoxically, represent both the continuity of working-class life, and the obliteration of some of its older traditional forms (both material and cultural). The tensions that underlie this shift are vital in understanding the structure of feeling from which Saturday Night and Sunday Morning is generated. 
The country, and by implication, residual forms of working-class culture are threatened by the expansion of the city within the representations of Saturday Night and Sunday Morning. Seaton's role in this is ambiguous. On the one hand, Seaton exemplifies this threat, he is, or has retrospectively become, the talisman of an emergent urban consumer culture. Yet, Seaton knows the fields and woods of the surrounding country 'like the back of his hand' ([1958] 1961: 42). Whilst the new houses built on the outskirts of the city are described as 'advancing armies' ([1958] 1961: 179), and the sawmill at the edge of the woods is 'set like the camp of an invader' ([1958] 1961: 42), Seaton navigates the landscape with an easy familiarity and level of care that sets him apart from these aggressive infractions. Seaton's relationship to the landscape provides the foundation for his relationship with residual forms of working-class cultures. These country vignettes are undoubtedly nostalgic in tone, and lack the historicity necessary to construct a recognisable knowable community. They do however, locate Seaton socially, geographically, and temporally in the North of England, where the industry of the individual has been incorporated into institutionalised heavy industry. Further, the lack of any sense of an historical development is in keeping with Seaton's character. Seaton sees not the nuances and processes of a specific local history, but 'then' and 'now' constructed as oppositional forms. The golden age of the independent craftsman, and the age of the indentured factory worker, all working to pay off televisions installed on the never never' ([1958] 1961: 22). Seaton himself exists outside of this dichotomy having 'settled' for the 'comfortable wage' of fourteen pounds a week ([1958] 1961: 25). This is his optimum income, carefully worked out so as to avoid the scrutiny of the tax man and the rate checker, in order that he might earn his living 'in spite of the firm' ([1958] 1961: 25). It is the freedom that this wage allows that provides Seaton with the opportunity to take his leisure in the country, thus reconnecting with the residual cultural forms, or at least his perceptions of them. Arthur Seaton represents an emergent form of working-class masculinity of the late 1950s. The juxtaposition of this young, fashionably dressed urban working-class male, recognizable to contemporary audiences as some sort of Teddy Boy, and the 'silence and peace' (Sillitoe, [1958] 
1961: 112) of the Nottinghamshire countryside, serves to underscore the societal shifts occurring in the wake of the war. Seaton is the young urban consumer writ large against nostalgic representations of rural England. The resistance, or discontinuity that this connotes is complicated by a number of facts. Seaton can be read as a continuation of a long tradition of radical workingclass protagonists (Haywood, 1997). However, his refusal of active political engagement and his pronounced individualism frame his resistance as something which diverges from traditional representations of class conscious radicals.

Seaton's engagement with fashion and his rebelliousness demonstrate the significance of emergent consumer driven youth cultures within this structure of feeling. As Nick Bentley notes, 'although Arthur is represented as an individualist throughout the text he negotiates two competing forces in his Bildungsroman narrative', these forces are, 'the working class of his parents' generation' and 'the new consumerist boom of the late 1950s' (2010: 25). I suggest that this dichotomy stretches beyond the parent generation to include older residual forms of working-class culture also, that Seaton's character is founded upon the continuation of traditional forms of workingclass masculinity, whilst many of his actions simultaneously destabilise those traditional forms. This is clearly apparent in Seaton's relationship with the country, where Seaton uses his knowledge of the local geography (and his cunning) to conduct illicit affairs with married women. His actions here undermine the older, more traditional forms of masculinity represented within the texts, the 'slow husbands' who treated their wives as 'ornaments and skivvies' ([1958] 1961: 36). Seaton attributes much of his 'success' with women to the fact that he can 'make woman enjoy being in bed', and 'make sure a woman got her fun' ([1958] 1961: 37) whilst he was getting his own. Whilst the language that communicates these revelations retains more than an air of sexism, Seaton's attitude toward such matters does demonstrate a shift in the discourse of sexuality, and sexual practice during this period. As Stephen Brooke notes, from the 1940s onwards 'it does seem that active and fulfilling sexual lives were increasingly perceived by women as crucial to companionate marriages and relationships' (2001: 783). However, this ostensibly radical departure from 
traditional forms of working-class masculinity is not as straightforward as it seems. As Peter Kalliney observes,

[Seaton] complicates his resistance to 'conventional' sexgender roles by eagerly anticipating his eventual identity as husband and primary wage earner, even adding this gender role to his sexual fantasies. In short, he develops an understanding of masculinity by simultaneously resisting and inhabiting the role of husband and breadwinner (2001: 94).

The representation of Seaton's relationship to the country, and its close connection to his sexuality and sexual practices, demonstrates how emergent masculinities were simultaneously formed upon, and in opposition to existing dominant and residual forms of working-class masculinity. Further, when considering Seaton's overall narrative trajectory, it becomes apparent how those emergent forms of masculinity are incorporated, and contribute to, a new configuration of a hegemonic masculinity that is specific to this structure of feeling. As Laing correctly observes, in this respect Seaton is 'the object, not the subject of his future' (1986: 68). Perversely, this is perhaps the most subversive and genuinely oppositional aspect of the text, demonstrating as it does, that despite the improved material conditions of many within the working-class of 1950s Britain, the horizon of expectations remains the same. Arthur Seaton is objectified and commodified (although the process of commodification is less explicit than that represented in This Sporting Life). As William Hutchings observes, the automatic nature of Seaton's actions at his lathe reduce him 'to mere operative extension of the factory's machinery' (1987: 35). Yet, Seaton's role at the factory situates him in a complex socio-political structure in which his objectification allows him to assume the subject-position of consumer. Seaton clearly benefits from the improved material conditions and increased affluence amongst the working-class. This is demonstrated by the construction of pre- 
war and post-war life as diametrically opposed states of being within the text. Pre-war consisting of 'the dole $[\ldots]$ and the big miserying that went with no money and no way of getting any', postwar, 'all the Woodbines he could smoke, money for a pint if he wanted one, $[\ldots]$ a holiday somewhere, [...] and a television set to look into at home' ([1958] 1961: 20). As Seaton states, 'The difference between before the war and after the war didn't bear thinking about. War was a marvellous thing in some ways, when you thought how happy it had made some people in England' ([1958] 1961: 20). The implication is that the welfare state and improvements to the material conditions of working-class life were born out of the ruptures of war. But, as Kalliney notes, ' $[\mathrm{w}]$ ithin the context of welfare state prosperity, ambivalence best describes a working-class political position: better material circumstances did not lead to a more equitable distribution of power, and Seaton's rage is a gendered response to this situation' (2001: 94). For Kalliney, Seaton's masculinity is formed through his simultaneous rejection, and inhabitance of the breadwinner role. That is to say that Seaton ultimately conforms to the underlying values of working-class society, even whilst, momentarily, resisting its norms. Kalliney presents the convincing argument that this is only made possible by the 'political and social circumstances of the welfare state when homes, jobs, and commodities all become more readily available to England's urban working-class' (2001: 94). Kalliney continues, 'Seaton fashions his masculinity through participation in consumption as well as through the role of family provider - both of which depend upon steady work and good wages' (2001: 94).

For Seaton, the practice of consumption incorporates the corporeal as well as the financial. The opening vignette of Saturday Night and Sunday Morning sees Seaton enter into a drinking competition with a loudmouthed sailor who reminds Arthur 'of a sergeant-major who once put him on a charge' ([1958] 1961: 6). There is a financial aspect to the exchange, as the contest will decide a wager where the 'Loser pays the bill' ([1958] 1961: 7). Here however, the focus is much more upon Seaton's physical ability to consume more than his opponent. In this context his victory over the sailor (after seven gins and ten pints of beer) is more than merely an opportunity of 'free 
booze' ([1958] 1961: 7). The contest serves as a symbolic resistance of traditional forms of masculinity through consumption, and demonstrates the emergent power of the youthful consumer. The fact that the wager is contested in the traditionally masculine arena of the pub demonstrates Seaton's connection to place and tradition. That is, it demonstrates that Seaton represents an emergent masculinity that generates from, and maintains, many of the internal structures of more 'traditional' masculinities, and dominant cultural forms. This in turn emphasizes the tensions between the continuities of working-class culture and new patterns formed from the dislocations of the 1950s, a fact which is further demonstrated in the form of the novel itself. The free indirect discourse employed by Sillitoe (to circumvent the problem of writing a novel from the perspective of 'a man who has never read a book' (Sillitoe quoted in Laing, 1986: 69)), ensures that, in part, Seaton is formally constructed by the voices of the community that surrounds him. For example, in the opening scene we see Seaton through the eyes of a group of rowdy singers in the bar, the waiter who discovers him at the bottom of the stairs, and the elderly man who steps over him thinking 'how jolly yet sinful it would be if he possessed the weakness yet strength of character to get so drunk' ([1958] 1961: 8). This last example further emphasizes a growing generation gap through its representations of Seaton's youthful, hedonistic rebelliousnes. In itself, Seaton's formal construction brings the tensions between continuity and dislocation within working-class culture into sharp relief. Despite Seaton's individualistic nature, his rebelliousness, his careful positioning of himself as outsider, without the subtle patchwork of voices that emanates from his community he would not exist. This problematises a reading of Saturday Night and Sunday Morning as a novel of escape. For all Seaton's pretentions - his refusal to drink the firms tea, the scorn he with which he thinks of 'slow husbands' ([1958] 1961: 36), his 'investment' ([1958] 1961: 56) in clothing - he cannot, and does not escape, as at a formal level he is constructed by the voices of his community.

Seaton describes himself as a rebel, explicitly stating his position in the soliloquy that opens the penultimate chapter. However, as Laing observes, '[t]he slippage between 'I' and 'you' in 
Arthur's reflections indicates how often they involve not so much his personal problems as his general condition - as a semi-skilled factory worker on piece-work' (1986: 70). I suggest that this view be expanded, that Seaton's reflections 'as a semi-skilled factory worker on piece-work' represent something of his generational condition. The replacement, or interchangeability, of the nominative singular pronoun, with the objective, plural 'you', serves to make the reader complicit in Seaton's thoughts, and suggests a collective disillusionment and disenfranchisement of not only manual workers, but more broadly, of post-war 'youth'. This is exemplified in the scene where Seaton is hit by a passing car - a symbol of consumerism and social climbing, and for Seaton 'pretentions' ([1958] 1961: 34) to be held against their owners. The driver of the car that strikes Seaton epitomizes this generational divide. He is the lower-middle-class everyman, his face 'ordinary', his height 'medium' ([1958] 1961: 99), he is an exemplar of 'the Establishment' against which youth identities were beginning to be defined. This is emphasized when, after the physical and metaphorical affront of being struck by the car, Seaton and his brother Fred are harangued by the man responsible: 'You bloody young fools' ([1958] 1961: 99 My emphasis). The man personifies the hypocrisy of 'the Establishment' when he accuses Seaton and his brother of being drunk whilst 'Waves of [his] whisky-breath came into their faces’ ([1958] 1961: 99). After more lies from the man about trying to warn them with his hooter, Seaton explodes with rage. To save the man from a severe beating, which at this point seems highly likely, Fred suggests that they tip over the man's car. Seaton agrees seeing this as 'perfect justice, punishment for both the actual metal that had hit him, and for the cranky driver' ([1958] 1961: 100).

The act which follows, however, takes on an even greater significance: 'Though locked in a revengeful act they felt a sublime team-spirit of effort filling their hearts with a radiant light of unique power and value, of achievement and hope for greater and better things' ([1958] 1961:100). The language here is reminiscent of that used in describing the war effort. The 'sublime teamspirit' and its resultant 'power', 'value' and 'achievement', and perhaps most significant of all, the 'hope for greater and better things', all represent definite assertions that are a long way in register 
from the slippages into second-person address that punctuate the majority of the text. In an inversion of contemporary value systems, the tipping of the car is the fulfilment of the war's potential for social change, and represents a moment of radical behaviour in which the attributes which were aligned with the 'hope for greater and better things' are realised, temporarily and in isolation, at home. This inversion operates in two specific, interrelated ways. First, it separates practices of consumption into conformism and individualism. To have a car is to conform to the prevailing consumer boom, whilst Seaton's own consumption represents a heightened individualism - although this is complicated by the fact that, in many ways, his consumption conforms to the emergent youth cultures of the 1950s. Second, this separation allows the tipping of the car to be viewed as a rejection of a certain type of consumerism, and thus, a political statement which rejects the compromises of the post-war settlement. Here Kalliney's reading of the text is particularly useful as it clearly demonstrates the paradoxes that underlie Seaton's position. First Seaton is only able to situate himself as outsider in the manner that he does because of the increased affluence and material improvements brought about by the welfare state. Second, and more significant, ultimately Seaton constructs his notion of masculinity upon, and measures his masculinity against the role of traditional working-class breadwinner, father, husband, and head of household. Thus, the tensions between residual and emergent forms of masculinity are apparent in the construction of Seaton's identity, whilst the narrative arc, and the success of the novel itself, demonstrates how they are incorporated into the dominant culture of the period. To put this another way, it is a hegemonic masculinity which ensures Seaton's relative class-position remains the same, despite the material improvements of increased wages, access to consumer goods, and enough disposable income to invest in clothing. This goes some way to explaining the sense of inevitability with which Seaton considers his future. Seaton ultimately becomes a man by conforming to the cultural construction of what it means to be a man within the confines of his class and his locality, and accepts his impending future as husband, father, and breadwinner with his girlfriend, Doreen, in the new Nottingham suburbs. 
Arthur Machin's relationship to domestication in This Sporting Life is complex. On the one hand, Machin revels in what Claire Langhamer refers to as 'family focused leisure' (2005: 341), though the family is that of the widowed Mrs. Hammond, and not his own. Despite this, Machin strongly resists the role of domesticated husband, whilst insistently being drawn towards it. Similar complexities exist within the configuration of Machin's class position, and become apparent where the construction of class and masculinity intersect. For example, Machin opts to stay in Mrs. Hammond's small terraced house, paying 'thirty-five bob a week' ([1960] 1963: 19) for a room of his own in the traditionally working-class area of the city. This is a move at odds with Machin's status as upwardly mobile bachelor, and local celebrity, but which allows Machin to enact the role of working-class breadwinner within Mrs. Hammond's modest house. It is left to Machin's teammate Maurice to assume the role of domesticated husband after being forced to marry Judith, the secretary of the local mayor, whom he has made pregnant. Judith and Maurice move into a 'semi-detached house' that is 'only a few years old' ([1960] 1963: 201). After the move Judith adopts the habit of calling Maurice, 'Morry' ([1960] 1963: 202), a pet name that indicates his new domesticated status. Maurice himself takes on domestic labour, such as digging the garden, and explicitly states that the move and his new roles are part of 'breaking away from the past life' ([1960] 1963: 207).

Despite opting to remain in the working-class area of the city in the enactment of the male breadwinner role, Machin's driving to the country represents a literal and metaphorical attempt to escape his class position. This is demonstrated by his 'conspicuous' independence, designed to show that he 'd[oesn't] really need to notice people anymore' ([1960] 1963: 80) as he enters the car. Machin does not have the same deeply personal relationship with the country as Seaton, although the country is still significant within the text. Machin's engagement with the countryside encapsulates a significant character trope as he meets the landscape either confrontationally, or, with an air of detached disinterest. At its crudest, the confrontation takes the form of a sort of conquering of nature, Arthur's Jaguar car eating up the country road, or his crossing the river with 
Lynda in his arms ([1960] 1963: 81). Significantly, this incident shows Machin defying Mrs. Hammond by taking her daughter across the fast-flowing stream after she has stated it is too dangerous, an unnecessary attempt to prove himself the hero, which inevitably causes Mrs. Hammond distress. During the episode we also see Machin imagining how he would feel if he 'was responsible for Lynda's drowning' ([1960] 1963: 82). A gesture toward emotion, which ultimately reveals the absence thereof, or rather an inability to connect to them directly, or articulate them satisfactorily. This is a recurrent theme within the representation of working-class masculinities and constitutes a major trope within the construction of Machin's character. Despite the absence of genuine emotional connection, the 'family focused leisure' of the country excursion is an important facet in Machin's fantasy of fulfilling the role of breadwinner in the formation of his masculine identity. However, the fact that Machin and Mrs. Hammond are not married undermines the institution upon which that role, and Machin's fantasy are structured, and, is the underlying cause of many of the tensions that exist between them. In relation to this the ruins of 'Markham Abbey' ([1960] 1963: 81) (where the crossing of the river occurs) are significant, as they represent a residual form of class power, and a crumbling religious rectitude. This is juxtaposed against Machin's Jaguar car (here a symbol of the emergent form of the upwardly mobile consumer), and the pretext of 'family' that informs the unmarried couple's outing. Tellingly, the sheep that inhabit the grounds of the abbey move around the car 'as if it were just another part of the ruins' ([1960] 1963: 81). Machin imposes himself on the scene by scooping up Lynda and crossing the river. However, the car is metaphorically swallowed by the country, an early indication of the precarious nature of Machin's superficial success, and the fluid nature of hegemonic control.

Howton Hall is 'an old country house converted into a hotel and an eating place for the sort of client that could afford to drive out there for an evening, or a weekend' ([1960] 1963: 84). Here again, Machin imposes himself upon the scene, displaying a bullish confidence that ultimately reveals a lack of cultural capital. As a result Machin appears out of place, or dislocated. Mrs. Hammond's presence in the scene is significant. Unlike Seaton, Machin's motivation in taking his 
landlady and lover out of town is not sexual. Rather, the country outings become representative of the dislocations that accompany social mobility and the improvement in material conditions experienced by the working-class during this period. Mrs. Hammond, older than Machin, represents a previous generation of the working-class, and carries with her a deep sense of shame and impropriety around the nature of their relationship. Machin, the young upwardly mobile man, revels in exploring the freedoms that his newfound power as a consumer affords him, but makes his lack of cultural capital increasingly evident as he does so. If, as suggested above, the presence of Mrs. Hammond and her children on the excursion feed Machin's patriarchal fantasies, then his actions during these scenes demonstrate that these fantasies do not operate simply at the level of emulation. In simultaneously adopting and consciously undermining, the role of middle-class patriarch, Machin actively challenges the dominant cultural values of middle-class society. Nowhere is this more evident than in the scene in which Machin takes Mrs. Hammond and her children for lunch at the exclusive restaurant at Howton Hall. Significantly, upon arrival at the restaurant Machin is wearing his football boots (his shoes having got wet carrying Lynda over the river at Markham Abbey). The football boots consolidate Machin's dislocation whilst explicitly symbolizing the means by which he has accrued his wealth and the ability to patronize such an establishment. When met by a pretentious waiter who, thinking they have 'strayed over to the wrong side of the hotel' ([1960] 1963: 85), takes pains to point out how expensive the menu is, Machin responds by ordering 'everything that cost the most' ([1960] 1963: 85).

Though lacking cultural capital, Machin has no insecurities about his taste. Rather, he imposes his masculine authority upon the scene through a blatant act of conspicuous consumption. Initially Mrs. Hammond is terrified, but as she eats the 'juicy food' ([1960] 1963: 85), Machin assumes that 'the indignity of coming to the place was somehow worth it' ([1960] 1963: 85). In contrast to Machin's brash authority, Mrs. Hammond represents the cultural dislocation associated with class mobility. Unsure of her own taste, she feels out of place, her habitus dictates that she does not have the cultural capital to 'pass' within the complex, yet 
unacknowledged social codes that govern behaviour within the restaurant setting. Machin's bravado serves to emphasize Mrs. Hammond's meekness as a symbolic dichotomy between an older, more 'traditional' working-class, encased within its own horizon of expectations, and a dynamic, upwardly mobile, masculinity, that typifies the shifting condition of an emergent English urban structure of feeling. This dichotomy is further underlined by the presence of Mrs. Hammond's dead husband's 'working boots' ([1960] 1963: 19), which she keeps polished on the hearth. Eric, Mrs. Hammond's husband, was killed in an industrial accident in the same factory at which Machin works as a lathe operator. Significantly, the factory is owned by Mr. Weaver, a patron and leading committee member of the rugby club for which Machin signs. The 'working boots' serve as a counterpoint to Machin's football boots, and evoke the spectre of an exploited and oppressed working-class masculinity. Whilst ostensibly the different boots demonstrate that Machin has moved beyond the role of exploited worker, the presence of the 'working boots' serve to remind us that this break is neither complete, nor absolute.

As the meal at Howton Hall concludes, the waiter, who here represents the establishment (the restaurant), and 'the Establishment', attempts to make Machin wait for his bill. Machin gives the waiter three minutes before rising to leave, again disrupting the social practices associated with the setting, symbolically challenging the cultural structures that underpin it, and imposing his own aggressive masculine presence. On being challenged Machin takes great pleasure in having the waiter check the bill repeatedly, before carefully counting out the money and leaving a sixpenny tip. Upon leaving Machin proclaims, 'We left Howton Hall with a sense of achievement' ([1960] 1963: 87), a clear indication of the subversive motives that have underpinned his behaviour. The episode emphasizes aspects of the performativity of classed masculinities, and how practices of consumption were increasingly assimilated into emergent forms of working-class masculinities during the 1950s. The conflation of money and food is also significant as it demonstrates both Machin's physical and economic ability to consume. The emphasis here however is clearly on the 
economic, the meal itself being secondary to Machin's ability to pay, and importantly, to do so on his own terms.

This Sporting Life is written entirely in the first person, the narrative structured around the hypermasculine subjectivity of Arthur Machin. Within the structure of the novel Machin is imbued with a sort of omniscience (a trait present in Saturday Night and Sunday Morning, but there the voice is less that of Seaton and more an overarching authorial voice). Machin is able to tell the reader how Mrs. Hammond is feeling, for example, though this perhaps says more about how women are constructed within this particular structure of feeling than it does about Machin's empathetic wisdom. Yet despite the first person narrative, Machin is repeatedly objectified throughout the text. As Alan Tomlinson points out, this begins with the 'onomatopoeic' [sic] properties of Machin's name; Machin suggesting making and macho (1999: 8), to this I would add machination, and significantly, machine. When told that it is a surprise that he feels 'so much about things' Machin responds by describing himself as a 'natural professional', adding, 'What I don't get paid for I don't bother with. If I was paid to feel then I'd probably make a big splash in that way' ([1960] 1963: 171). Indeed, in his capacity as a professional rugby league player, Machin is paid not to feel, to disregard physical pain and to abjure empathy as he inflicts pain upon others. Paradoxically, it is in Machin's professional lack of feeling that his connection to community becomes most apparent. The community of the team is founded upon self-sacrifice. As Donald Sabo observes:

The pain principle is crudely evident in the 'no pain, no gain' philosophy of so many coaches and athletes....It stifles men's awareness of their bodies and limits our emotional expression. We learn to ignore personal hurts and injuries because they interfere within 'efficiency' and 'goals' of the 'team'....We become adept at taking the feelings that boil up inside us....and channeling them in a bundle of rage which is directed at opponents and enemies (Sabo quoted in Messner, 1992: 61). 
There is a distinct sense in the text however, that Machin's sacrifice to the team is by no means unconditional. Rather, the sacrifices and pain he endures are part of a transaction in which he achieves the status of hero, and the adoration of his fans. Machin revels in his ability to make the crowd cheer and roar, and, to some degree, the attention he receives off of the field. On being recognised in the city Machin states:

They made me feel I owned the place. Course I strutted about. They expected it. I couldn't help it. I walked in front of these people now, and I felt the hero. They wanted me to be a hero - and I wanted to be a hero ([1960] 1963: 162).

The nature of the transaction between Machin and the public is clearly apparent here. They make him feel, and in the process elevate him to the position of hero, a transaction of mutual benefit. This transaction is not without its complications however, as Jenni Calder notes:

The sporting hero retains the characteristic duality, i.e. aggressive, and officially supported, anarchist and institutionalized, testing himself privately for the benefit of thousands who want to reward him with adoration and imitation. He is both representative and elite, collective and individual. In many respects he is a very satisfactory hero for he can be controlled; the world in which he operates and in which he can succeed is limited (Calder quoted in Whannel, 2002: 44-5). 
There is a clear divide in the text between the element of the transaction that feeds Machin emotionally, his power on the field; and his emotional deficiencies off the field, where his brutishness and the absence of feeling result in failure. Machin struggles to cope with the precariousness of his social position, and the lack of control he experiences off the field of play.

I wasn't going to be a footballer forever. But I was an ape. [... No feelings. It'd always helped to have no feelings. So I had no feelings. I was paid not to have feelings. It paid me to have none. [...] Walking up the road like this they looked at me exactly as they would look at an ape walking about without a cage. They liked to see me walking about like this, as if the fact I tried to act and behave like them added just the right touch the next time they saw me perform. [...] It was just what they needed when they saw me run on to the field, just the thing to make them stare in awe, and wonder if after all I might be like them. I might be human ([1960] 1963: 164).

Machin's size and physical power become a central theme throughout the text. He frequently refers to how big he is, or feels. It is this physical prowess that affords Machin the potential to break through the restrictions of class stratification. This is tempered however, by the fact that we a first introduced to Machin broken and infantilised. His front teeth smashed in the scrum, he is taken to the 'Children's Dental Centre' ([1960] 1963: 15) for emergency treatment. The juxtaposition of the large powerful man, injured, vulnerable, and, in the dentist's chair of the 'Children's Dental Centre', literally in the position of a child, takes the imposition of youth upon traditional structures of working-class masculinity to its limit. The implied childishness here suggests an underlying petulance in the subsequent subversive action embedded within the text, that poses questions about the oppositional position adopted by Machin, and more broadly, by the text as a whole. 
There is an adolescent quality to many of the male protagonists constructed within texts associated with the 'Angry' structure of feeling. As Tomlinson observes, a common theme in these novels is, 'the doomed, usually repressed, passion of a barely articulate masculinity and its desire for an adult love and real emotional relationships' (1999: 8). A significant moment in This Sporting Life sees this theme intersect with the theme of escape. Alone and isolated after the breakdown of his relationship with Mrs. Hammond, Machin seeks sanctuary in his car (a potent symbol of both his masculinity, and his power as an upwardly mobile consumer). In an attempt to emulate one of his American novellas, Machin naïvely tries to escape his troubles by leaving town.

I even tried driving out of town fast. But the roads were crammed. [...] And I'd only go a couple of miles before I was in the next bloody place. One started where the other left off. There was no place to feel free. I was on a chain, and wherever I went I had to come back the same way ([1960] 1963: 191).

The tension between Machin's power as a consumer - the car affords him the ability to drive out of town - and the limitations of his horizon of expectation - the world in which he operates and can succeed is clear. Machin is free to drive wherever he pleases, but the geography, and the social conditions in which he is situated ensure that he always ends up back where he started. He has the power to consume, but is trapped within a system that ultimately keeps him in his place. As Laing notes, 'the landscape of the industrial North deflates the fantasy and constrains the possibilities of Arthur's whole life' (1986: 73). In many ways the text deals specifically with the composition of Machin's fantasies, and their ultimate deflation. Machin's power is transient and the fantasies cannot be consolidated in any real and lasting way.

Machin has no particular passion for rugby, other than as a means of keeping his 'head above the general level of crap' ([1960] 1963: 19). The 'feeling of power' of being 'big' and 'strong' 
and being able to 'make people realize it' ([1960] 1963: 22) must inevitably end. By the final passage of the novel, which takes place ten years after the narrative begins, Machin is 'ashamed of being no longer young' ([1960] 1963: 251). His ability to sustain his part of the transaction between himself and the crowd is waning, Machin now enters each game knowing that 'one mistake, $[\ldots]$ and the whole tragedy of living, of being alive, would come into the crowd's throat and roar its pain like a maimed animal' ([1960] 1963: 252). Machin's connection to the local community is severed by his inability to perform as he once had, he ends the game with 'mud covering [his] tears' after his legs have 'betrayed’ him ([1960] 1963: 252). Machin's earlier failure to invest and start a business with Maurice suggests that the money he has made from playing rugby league will also soon begin to wane. As Laing points out, 'Maurice's plans for a business venture show how, unless the players use their temporarily higher income to secure their future, their status quickly evaporates' (1986: 71).

As Hutchings observes, it is telling that 'This Sporting Life ends in the locker-room rather than on the playing field itself because the latter is the site of the devalued commercial ritual that the game has become' (1987: 43). By contrast, the locker-room is the site of masculine rituals which are rooted in the community of the team. It is here that Machin feels he belongs, rather than the field, where he belongs to the club. This divide is predicated upon the commodification of workingclass masculinity, a central a theme of the text that is clearly demonstrated in the scene where Machin signs on as a professional. Before negotiations over Machin's signing on fee even begin he is framed as something to be consumed. Machin is 'shown into the committee room' ([1960] 1963: 50) where Wade presents facts about Machin to the committee, 'so we can see our meal before we eat it. So to speak' ([1960] 1963: 51). During the negotiations Machin is framed as machine, 'mechanically' repeating 'Five hundred down' ([1960] 1963: 55), until the signing is finally confirmed. Machin's objectification is complete as, upon signing, he observes, 'Weaver shook my hand softly and looked right into my eye with a kid's delight at a new toy' ([1960] 1963: 57). This objectification is consolidated when Weaver, whose name paradoxically suggests both dodging and 
bringing together, and in West Yorkshire (where the novel is set) perhaps gives an indication of the origin of his family's wealth, drives Machin home. Machin observes, 'I could feel him polishing me and putting me on the shelf as his latest exhibit' before Weaver explicitly states that Machin is now 'property of the City' ([1960] 1963: 60).

Throughout the text Machin is both fetishized and emasculated. Fetishized as he is represented as the exotic, or dangerous, 'other' within the interclass and intergender relationships that are constructed within the text. The women Machin meets call him 'Tarzan' ([1960] 1963: 131), he is 'the big ape [...] known and feared for his strength' ([1960] 1963: 163). Emasculated through his infantilisation at the 'Children's Dental Centre', a trope which is further developed in the text (Machin repeatedly refers to Johnson, the scout who vouches for him, as 'Dad' for example), and is emphasized during the negotiations for Machin's signing on fee. There, Machin is repeatedly referred to as 'lad' and specific mention is made of the fact that he has not played since leaving school ([1960] 1963: 51). Further reference is made to the fact that Machin is unmarried, and has 'no legal ties with anyone - home or anything' ([1960] 1963: 51), this serves to undermine his relationship with Mrs. Hammond and the responsibility he feels toward her children, and strips Machin of the breadwinner status which is central to contemporary configurations of traditional working-class masculinity. A key figure in both the fetishisation and emasculation of Machin is Weaver. Weaver's assertion that Machin is 'property of the city' ([1960] 1963: 60) is significant as it makes explicit the fact that Machin has been bought, and now belongs to the club. Further, it suggests that Machin belongs to the city as a whole, that he is somehow tied to the place (both geographic and social) of his birth. This duality is emphasized by the description of Eric Hammond's death at Weaver's factory which immediately follows. Thus, at the moment Weaver makes the assertion, he is framed as both influential committee member, and industrialist, establishing a connection between Machin as player and Machin as factory worker. Both player (Machin), and worker (in this instance Eric) are dehumanised and commodified, as their worth is reduced to a monetary transaction. For Machin it is the five hundred pound signing 
on fee, for Eric the fact that Weaver's abiding memory of the incident is that the firm did not pay Mrs. Hammond compensation. The difference between the individualist social climber, and the traditional - though absent - paternal working-class figure, is marked. Eric is literally killed by his work and is ultimately worth nothing. Machin inherits his position within the house and is worth five hundred pounds.

There are elements of the bourgeois ladder model of escape from the working-class within the text: each man, through his own application, industry and hard work can potentially climb out of his working-class origins. Although as Williams observes, the ladder 'is a device which can only be used individually: you go up the ladder alone' ([1958] 1983: 331). With his increased economic capital, and his position as local celebrity and sporting hero, Machin is climbing the social ladder. His attachment to place and refusal to move from Mrs. Hammond's small terraced house emphasize his increased power as consumer, but isolate him as an individual and leave both him, and Mrs. Hammond, open to what Richard Hoggart describes as the 'harsher [...] sanctions' ([1957] 1977: 80) of the working-class community that surrounds them. As Mrs. Hammond tells Machin during the heated exchange that sees her insist that he leave:

They all point you out. [...] They think you're trying to be different. They all point you out. And they point me out. And Lynda. And Ian. We're not proper people now because of you ([1960] 1963: 175).

Ultimately Machin is disillusioned with the limited social mobility he is able to achieve. This is beautifully illustrated by the events at Weaver's Christmas Eve party, the climax of Part One of the novel. The chapter begins with a sort of enjambement in which the meaning of the previous episode (the last of Machin's flashbacks) is carried over. The previous chapter sees 
Machin challenge his father, questioning 'Where have your ideals got you?' ([1960] 1963: 112). Symbolically this is more than simply a son's challenge to a patriarch, it is a challenge to a traditional working-class patriarchy, and a traditional working-class culture more broadly. Machin's father repeats the question bewildered:

'Where?' He stared round him as if it was too obvious where his ideals had got him, where Mrs Shaw's ideals next door had got her, and Mr Chadwick's beyond her had got him. It was only too obvious ([1960] 1963: 112).

There follows a moment of recognition, when looking through his son's eyes, Machin's father sees 'the neighbourhood without its affectations and feelings, but just as a field of broken down ambition' ([1960] 1963: 112). The chapter ends with his father,

just sat there, the little man with no trousers, his head shaking from side to side in bewilderment, his face screwed up with inadequacy and self-reproach, half-blinded with tiredness and with life-fatigue ([1960] 1963: 112).

The opening of the following chapter is ambiguous, as it begins with the last of Machin's anaesthetically induced dreams. Still feeling the effects of his dental surgery Machin has fallen asleep in an upstairs bedroom at Weaver's Christmas party. The chapter begins:

I can see his face, creased in the darkness, racked with a pain that seems to grow steadily. Between us is a wall of pain that 
grows and thickens until it absorbs us both. It runs across my

face in dull spasms. It wakes me ([1960] 1963: 112).

The image of the face carries over the chapter break suggesting the face Machin sees is that of his father. Machin's father works 'nights on the railway' ([1960] 1963: 108), perhaps the reason the face is 'creased in the darkness'. Significant here is the pain that both divides - the pain 'is a wall' - and unites - the pain 'absorbs [them] both'. In a literal sense, this refers to the physical pain caused by their labour (Machin's tongue is resting on the empty front sockets of the removed teeth when he comes round). However, underlying this there seems to be an emotional pain, common to father and son, caused by the generational dislocation. When he awakes at the party Machin finds himself locked in an upstairs bedroom, literally locked into the decisions he has made. Significantly he is alone and begins to 'feel the need to get out of the room' ([1960] 1963: 113). In contrast, his father, though purportedly trapped in 'a field of broken down ambition' still has the community of Mr. Chadwick and Mrs. Shaw ([1960] 1963: 112). Machin achieves his escape by climbing out of the window and slotting his elbows into the guttering. Here, both literally and metaphorically, Machin has climbed as high as he can go, and still ends up in the gutter, hanging precariously.

Upon reaching the ground Machin encounters Wade, who is looking for his lost dog in the garden. Wade explicitly warns Machin of the 'risks of ownership' ([1960] 1963: 115). This ostensibly insignificant comment about a dog is developed throughout the remainder of the text. For example when Machin publicly insults Mrs. Hammond, Maurice unambiguously echoes the encounter with Wade, telling Machin, 'She's not a dog you've trained or bought [...] you talk as if you owned the woman' ([1960] 1963: 149). Beyond this there are numerous references to owning and buying people as the commodification of the working-class is represented through the framing of relationships in transactionary terms. The dog motif continues as Machin finds himself back in 
the party with Weaver and Slomer (the two most influential and viciously opposed committee members). Upon entering the room Machin notices 'an elaborate tapestry of a hunting scene: the dogs have just got their teeth into a small, pale animal, and it's already dripping blood' ([1960] 1963: 117). Slomer is physically deformed, described variously as 'thin', 'white', 'the cripple', and 'a prematurely aged boy' ([1960] 1963: 118-9), echoing the description of the quarry represented on the tapestry. However, Machin's physical prowess is here redundant, in this company he is reduced to 'the court jester, big and dumb, a centre of confidential amusement' ([1960] 1963: 119). Machin is not feared for his size and brutality here, he is observed for entertainment. His size coupled with the adjective 'dumb' suggest both inferior intelligence and the lack of a voice. In this environment Slomer 'seems to suggest his deformity is the only proper shape for a body' ([1960] 1963: 119), an illustration of a self-assured power that transcends physicality. Even Machin's power as a consumer is taken away from him, when Slomer instructs him to 'drink up young man' ([1960] 1963: 117) the glass in his hand is already empty. Eventually it is Slomer who gives Machin permission to leave the room, 'he should be with people his own age downstairs and not with us tired old dogs' ([1960] 1963: 119), and in doing so reverses the symbolic imagery of the tapestry. It is Machin that is the quarry, Weaver and Slomer are the dogs. In short, there is no escape for Machin. Despite his perceived social climbing, his power as a consumer and improved material conditions, he is variously objectified, commodified and emasculated, and though dislocated, is ultimately static.

The limits of the horizon of expectation that are represented within these texts are symptomatic of the hegemonic control that pervades society. Further, the representation of the incorporation of emergent and residual cultural forms into the dominant, gendered, class structure, is reproduced in the material conditions of production that allow for the generation of this particular structure. That is to say, the perceived anger, and class-position of writers from divergent cultural positions and backgrounds 'proved a highly saleable commodity' (Maschler, [1957] 1959: 8). It is worth returning here to the label 'Angry Young Men', and considering the value of a label 
that incorporated writers as diverse as Kingsley Amis and Arnold Wesker. Indeed, the term 'incorporated' carries great significance. As Maschler's assertion that the writers which formed this pattern were 'rendered harmless in the AYM cage' ([1957] 1959: 7) suggests, the 'Angry Young Men' label became a means of commodifying a diverse range of dissenting voices, thus incorporating them into the dominant social structure. A paradox then emerges, as in a context where anger is 'a highly saleable commodity' (Maschler, [1957] 1959: 8), 'the AYM cage' (Maschler, [1957] 1959: 7) also becomes a platform from which to speak. It was that platform, and those dissenting voices, which provided the material conditions that became the foundation for the development of the Northern realism which emerged toward the end of the 1950s, which in turn produced a 'working-class moment' in British culture. That 'working-class moment' continued into the 1960s and is epitomised by figures such as The Beatles, George Best, David Bailey, Michael Caine and Terrence Stamp, all of whom can be viewed as being in some wat representative of the 1960s, each of whom would acknowledge, and in some instances, celebrate their working-class origins. Each would alter the cultural field in which they operated, and all would achieve global celebrity status. The development of a broader working-class moment is evident in the correlative relationship between the success of the Northern realist novels and their New Wave cinema adaptations. As Laing notes, the Pan paperback edition of Saturday Night and Sunday Morning was first published in 1960 - the same year that the Woodfall film adaptation was released - and had been reprinted thirteen times by 1964 (1986: 64-5). What emerges as the 1950s draw to a close is a pattern in which a certain kind of working-class masculinity is itself commodified.

The commodification of working-class masculinity is apparent in the structural regularities of the texts discussed above. Each features a disillusioned male protagonist that bears some resemblance to their author. Sillitoe acknowledged that Saturday Night and Sunday Morning was the result of 'bringing [his] experience from the Forties into the Fifties' (Sillitoe quoted in Laing, 1986: 66 ). Whilst This Sporting Life was written at a time when, after signing a fourteen year contract to play professional rugby league for Leeds, and being accepted at the Slade School of Fine Art in 
London, Storey spent his time travelling between the two by train, writing a novel about the alienation he was experiencing as a result (Campbell, 2004). Both are characterised by anger, ambiguity and alienation. Each epitomises a specific type of working-class masculinity, which, whilst different, are structured upon common uncertainties of the period. Primary amongst these are the combative relationships with the opposite sex, characterised by simultaneous feelings of entrapment and isolation, and by the protagonist's need to assert his masculinity in various, but often aggressive and oppressive ways. This in itself relates back to what Deborah Philips refers to as 'the loss of a heroic masculinity' (2006: 22), or as Osborne's Jimmy Porter would have it, the lack of 'good, brave causes' ([1957] 1973: 84) in the wake of the Second World War. Seaton and Machin are characters who are old enough to remember the war, but not old enough to have fought in it. Old enough to remember the promises of a better, fairer England, young enough to benefit from the material gains of the consumer boom of the 1950s, but savvy enough to question what had really changed.

Of course, these themes manifest in various ways across the texts, but the protagonists' responses vary little. Both adopt a selfish individualism in order to reaffirm their masculinity. In doing so each enacts an approximation of a specific kind of traditional working-class masculinity, yet simultaneously represents an emergent cultural force generated from within this structure perhaps even a new formation. Whether it be Jimmy Porter and his university education, Arthur Machin's engagement with the practices of consumption that Hoggart terms 'shiny barbarism' ([1957] 1977: 193), or the power of Arthur Seaton's youthfulness. Equally the pattern which is formed by the representation of these emergent masculinities, itself represents an emergent cultural form. In each case the protagonists, and often their authors, act outwith the cultural norms of the contemporary structure, resisting residual conservatism, and superficially opposing the Establishment. In each case there is an authentic attempt to present an oppositional form. However, this is undermined by the very individualism with which it is enacted, as ultimately, though dislocated, the characters remain socially static and are forced to embrace residual social 
positions in order to consolidate their own masculinity. Whilst in a broader context, that masculinity itself is commodified and sold, making both characters and authors, quite literally, a product of their time.

Allsop, K. (1964), The Angry Decade, London: Peter Owen Limited.

Bentley, N. (2007), Radical Fictions: The English Novel in the 1950s, Oxford: Peter Lang.

Bentley, N. (2010), 'New Elizabethans': The Representation of Youth Subcultures in 1950s British Fiction. Literature and History, 19 (1): 16-33.

Brooke, S. (2001), Gender and Working Class Identity in Britain During the 1950s. Journal of Social History, 34 (4): 773-795.

Campbell, J. 2004. A Chekhov of the North. The Guardian [Online]. Available: http://www.theguardian.com/stage/2004/jan/31/theatre.stage [Accessed 02/07/2015].

Ferrebe, A. (2005), Maculinity in Male-Authored Fiction 1950-2000: Keeping it Up, Basingstoke: Palgrave Macmillan.

Haywood, I. (1997), Working-Class Fiction from Chartism to Trainspotting, Plymouth: Northcote House Publishers Ltd.

Hoggart, R. ([1957]1977), The Uses of Literacy, London: Penguin.

Hopkins, E. (1991), The Rise and Decline of the English Working Classes 1918-1990, London: George Weidenfeld \& Nicholson Ltd.

Hutchings, W. (1987), The Work of Play: Anger and the Expropriated Athletes of Alan Sillitoe and David Storey. Modern Fiction Studies, 33 (1): 35-47.

James, D. (2008), Contemporary British Fiction and the Artistry of Space, London: Continuum.

Kalliney, P. J. (2001), Cities of Affluence: Masculinity, Class, and The Angry Young Men. Modern Fiction Studies, 47 (1): 92-117.

Kroll, M. (1959), The Politics of Britain's Angry Young Men. The Western Political Quarterly, 12 (2): 555-557.

Laing, S. (1984), Room at the Top: The Morality of Affluence, in: Pawling, C. (ed.) Popular Fiction and Social Change, New York: St. Martin's Press.

Laing, S. (1986), Representations of Working-Class Life 1957-1964, London: MacMillan Publishers Ltd. Langhamer, C. (2005), The Meanings of Home in Postwar Britain. Journal of Contemporary History, 40 (2): 341-362.

Mansfield, J. (2010), The Brute-Hero: The 1950s and Echoes of the North. Literature and History, 19 (1): 34-49.

Maschler, T. (ed.) (1959), Declaration, London: MacGibbon and Kee.

Messner, M. A. (1992), Power at Play: Sports and the Problem of Masculinity, Boston: Beacon Press.

Osborne, J. ([1957] 1973), Look Back in Anger, London: Faber and Faber.

Philips, D. (2006), Women's Fiction 1945-2005: Writing Romance, London: Continuum.

Sillitoe, A. ([1958] 1961), Saturday Night and Sunday Morning, London: Pan Books Ltd.

Storey, D. ([1960]1963), This Sporting Life, London: Penguin Books Ltd.

Tomlinson, A. (1999), David Storey's \& Lindsay Anderson's This Sporting Life: Reflections on the Aestheticisation of the Sporting Body. Diegesis: Journal of the Association for Research in Popular Fictions, Summer (4): 6-13.

Whannel, G. (2002), Media Sport Stars: Masculinities and Moralities, London: Routledge.

Williams, R. ([1961] 1965), The Long Revolution, London: Pelican.

Williams, R. ([1973] 1975), The Country and the City, London: Paladin.

Williams, R. (1977), Marxism and Literature, Oxford: Oxford University Press.

Williams, R. ([1958] 1983), Culture \& Society: 1780-1950, New York: Columbia University Press.

Williams, R. \& Orrom, M. (1954), Preface to Film, London: Film Drama. 
